\title{
Construction of Transmission Box Fault Diagnosis System
}

\author{
Hongbo Zhu*, Youkun Zhang and Tongjie Shi \\ College of Automotiv Engineering, Jilin University, Changchun, China \\ ${ }^{*}$ Corresponding author
}

\begin{abstract}
This paper established a set of fault diagnosis system for the fatigue test of the drive axle and transmission. The fault diagnosis system includes two parts: hardware and software. The hardware part is the basis of data acquisition and warning signal output; the software is programmed to realize human-computer interaction, data sampling and storage, signal processing and fault diagnosis on the basis of hardware. In this paper, we introduced a fault diagnosis method based on vibration analysis and the concept of feature vector, according to the feature vector could determine the fault type. Finally, the reliability and practicability of the system are verified by a laboratory test.
\end{abstract}

Keywords-vibration analysis; fault diagnosis; transmission

\section{INTRODUCTION}

The transmission box fault diagnosis system we constructed, which based on drive axle and transmission signal failures characteristics and signal processing, by detecting the vibration signal of the cabinet, under the premise of non-stop running and without unpacking, we want to realize the function of real-time monitoring and fault detection of the test bench. It's able to give warning at the initial time and make fault diagnosis.

\section{HARDWARE AND SOFTWARE}

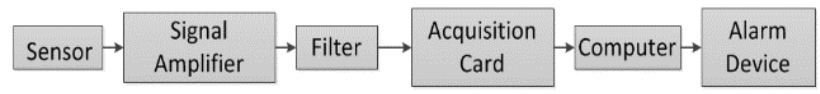

FIGURE I. HARDWARE SYSTEM DIAGRAM

Figure I is the hardware system diagram. The hardware part is based on the analysis of the vibration signal acquisition process and the output of the early warning signal, including the sensor, signal amplifier, filter, acquisition card, computer and alarm device [1]. We used the SD type piezoelectric acceleration sensor to measure the vibration signal, used the three wire CM12-45P-1-24 Holzer speed sensor to measure the speed signal, and used the PT100 temperature sensor to measure the temperature signal. This system used SD-5A charge amplifier as the filter amplifier. It used the NIPCI-6014 data acquisition card as the AD/DA conversion element, which can realize the function of outputting the vibration acceleration signal and the speed signal acquisition, the early warning signal and so on. The peripheral circuit includes the power module, the wireless transmission module, the indicator light, the switch and so on, we assembled all the components in the same box. The computer is used to realize the function of data storage and processing. When a fault is detected, the computer will send out the alarm signal, through the I/O module of the acquisition card to output the signal to the signal alarm device, the signal will control buzzer sends out alarm sound and light the fault indicator light. Part of the hardware is shown in Figure II. Figure 2a is peripheral circuit integrated box, Figure $2 b$ is the signal receiver and alarm device.
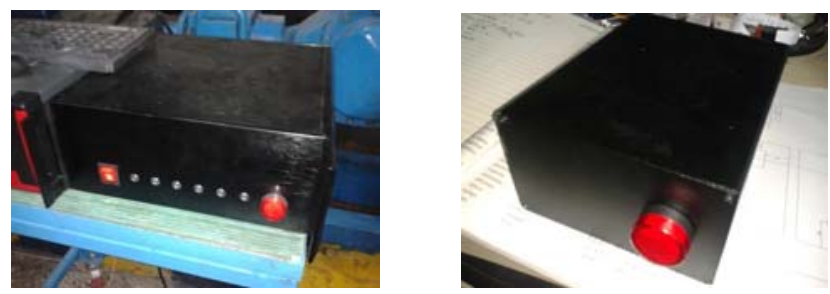

FIGURE II. FIGURE 2A INTEGRATED BOX, 2B SIGNAL RECEIVER AND ALARM DEVICE

Figure III is the software system diagram. The software part is written on the Matlab software platform, which is divided into two parts: user interface, data processing and fault diagnosis.

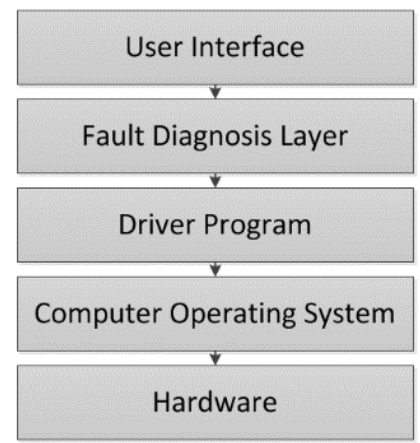

FIGURE III. SOFTWARE SYSTEM DIAGRAM

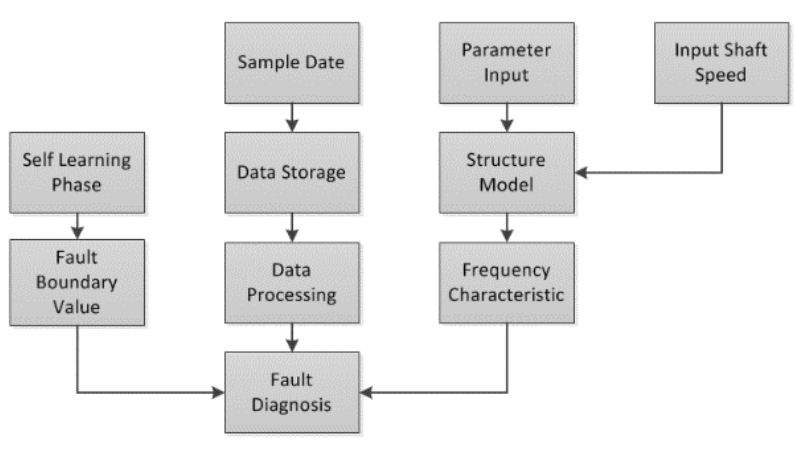

FIGURE IV. DATA PROCESSING AND FAULT DIAGNOSIS PROGRAM FLOW CHART 
The user interface is written by using Matlab software, its GUI module provides a powerful interactive interface.

Figure IV is the data processing and fault diagnosis program flow chart. This system has established a modular program, including data storage module, self-learning module, signal processing module, fault diagnosis module, as well as the various types of drive axle and transmission structure parameters and fault parameters database.

\section{FAULT IDENTIFICATION STRATEGy AND FAULT DIAGNOSIS EXAMPLE}
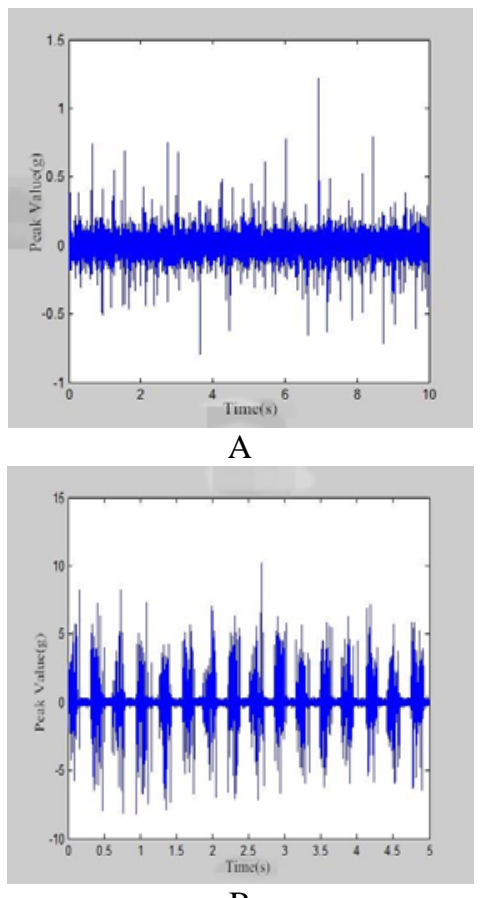

FIGURE V. 5A TIME DOMAIN SIGNAL OF TOOTH SURFACE DAMAG, 5B TIME DOMAIN SIGNAL OF BROKEN TEETH

Figure $5 \mathrm{a}$ is the time domain signal of tooth surface damage [2], Figure 5b is the time domain signal of broken teeth [3]. According to the common fault of drive axle and transmission, we summarized and analyzed the feature of the signal then obtained some empirical rules [4]:

(1) The gear meshing frequency and its harmonic amplitude increase, there is no band: generally is the gear wear, the radial clearance is too large, the gear load is too large;

(2) The gear meshing frequency and its harmonic amplitude are increased, and the amplitude of harmonic wave increases relatively: gear wear;

(3) There is a modulation phenomenon in the frequency spectrum, the frequency band of the frequency and its harmonics appear on both sides of the band, and the frequency band is the frequency of a certain axis: an uneven distribution of faults, such as a change in pitch;

(4) Frequency modulation phenomenon occurs, but only the lower frequency band, the upper frequency band is very small: eccentric gear;
(5) The spectrum is modulated, the number of side bands is more and dispersed, the shape of the side band is changed with the development of the fault: local fault such as the tooth surface spalling, cracks, broken teeth and so on;

(6) The frequency spectrum of the tooth is modulated, the frequency of the side band is small and concentrated, the amplitude and distribution of the frequency band are changed with the development of the fault: pitting and other distributed faults;

(7) In the time domain, the upper and the lower envelope of the carrier signal are asymmetric, and there are no side bands in the frequency spectrum: gears are unbalanced or mechanically loose.

Making use of the above rules can easily judge the typical faults by the spectrum characteristics. O determine the structure parameters of drive axle and transmission, combined with the features of fault signals, the feature vector of each type of fault is established, which is a one-dimensional array can represent the fault features. The fault type can be obtained by judging the feature vector.

Using the driving axle driving gear as an example: the number of teeth is $n_{1}$, the input shaft rotation frequency is $f$, the feature vector of driving gear is established. The meshing frequency and the two sides of the interval of one times, two times and three times of rotating frequency, the side frequency corresponding the amplitude which can constitute a one-dimensional array, the vector form is: $\left(\mathrm{n}_{1} * \mathrm{f}-3 \mathrm{f}, \mathrm{n}_{1} * \mathrm{f}-2 \mathrm{f}\right.$, $\mathrm{n}_{1} * \mathrm{f}-\mathrm{f}, \mathrm{n}_{1} * \mathrm{f}, \mathrm{n}_{1} * \mathrm{f}+\mathrm{f}, \mathrm{n}_{1} * \mathrm{f}+2 \mathrm{f}, \mathrm{n}_{1} * \mathrm{f}+3 \mathrm{f}$ )

We can obtain a benchmark vector F0 during the learning phase, the vector is F1 After the occurrence of the fault, the feature vector is defined as (F1-F0)./F0. According to the value of each component of the feature vector, we can judge whether the drive gear has faulty and its type. If only the middle value which corresponded to the center frequency is larger, it is the uniform wear of the driving gear, if the middle value and the both sides value is bigger, it is the occurrence of uneven faults such as local wear. We have sorted out the feature vectors of typical fault so far, which can be further enriched by the accumulation of future experiments.

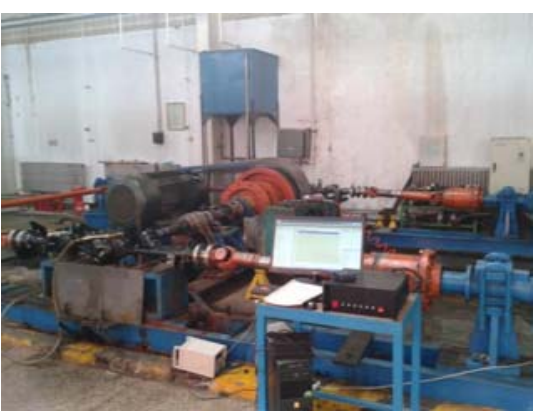

FIGURE VI. TEST LAYOUT

Figure VI is the test layout. We carried out the drive axle fatigue test in the automotive laboratory, the main and auxiliary driving axle tested at the same time, input speed was 200rpm, sampling frequency was $1000 \mathrm{~Hz}$, running - in period was 6 hours, then manual stopped and loaded, full load torque was 
$1000 \mathrm{Nm}$, the target input revolutions was 500 thousand, but this test stopped in 14 hours about 170 thousand RPM because of the active bevel gear tooth crack. We analyzed the signal at the end of the test.

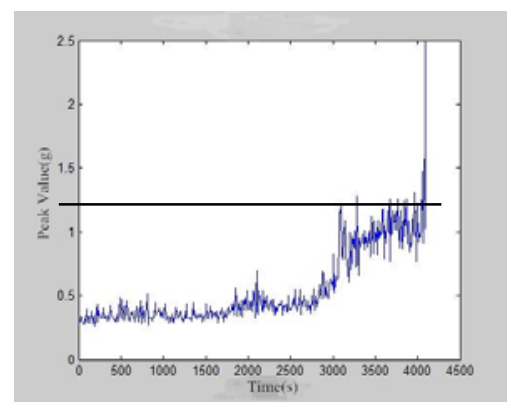

FIGURE VII. TIME DOMAIN PEAK

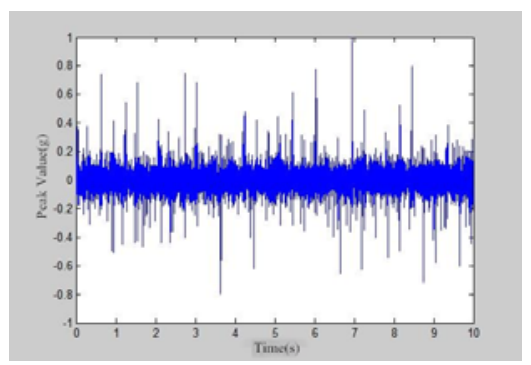

FIGURE VIII. SIGNAL AT 4000S

Figure VII is the peak time domain curve of the vibration signal of the box for about 4100 seconds before stopped, alarm limit value was $1.35 \mathrm{~g}$. It can be seen from Figure VII that the peak value of the time domain shows a rising trend with the aggravation of the fault. We extracted the signal of 4000s in time domain. Figure 8 is the time domain signal at 4000s, it can be clearly seen that there are a lot of spikes in the time domain signal in 4000s, which shows that the vibration of the bridge shell is intensified, and the internal fault tends to be serious. Made the frequency domain analysis of the time domain signal, to establish a three-dimensional spectrum, show in Figure IX.

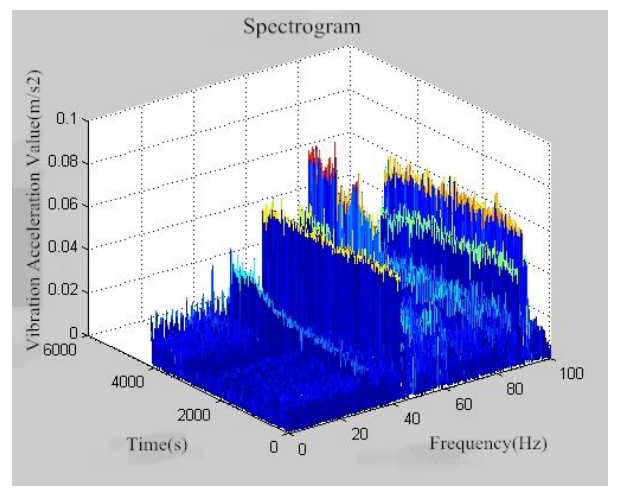

FIGURE IX. THREE-DIMENSIONAL SPECTRUM

We can get three time points of the vibration signal spectrum by intercepting respectively in the vertical coordinate $10 \mathrm{~s}, 4000 \mathrm{~s}$, and the beginning of the test of the vibration signal in the frequency domain, show in Figure 10. Figure 10a is the spectrum at the beginning of the test, Figure $10 \mathrm{~b}$ is the spectrum at 10s, Figure 10c is the spectrum at 4000 s.
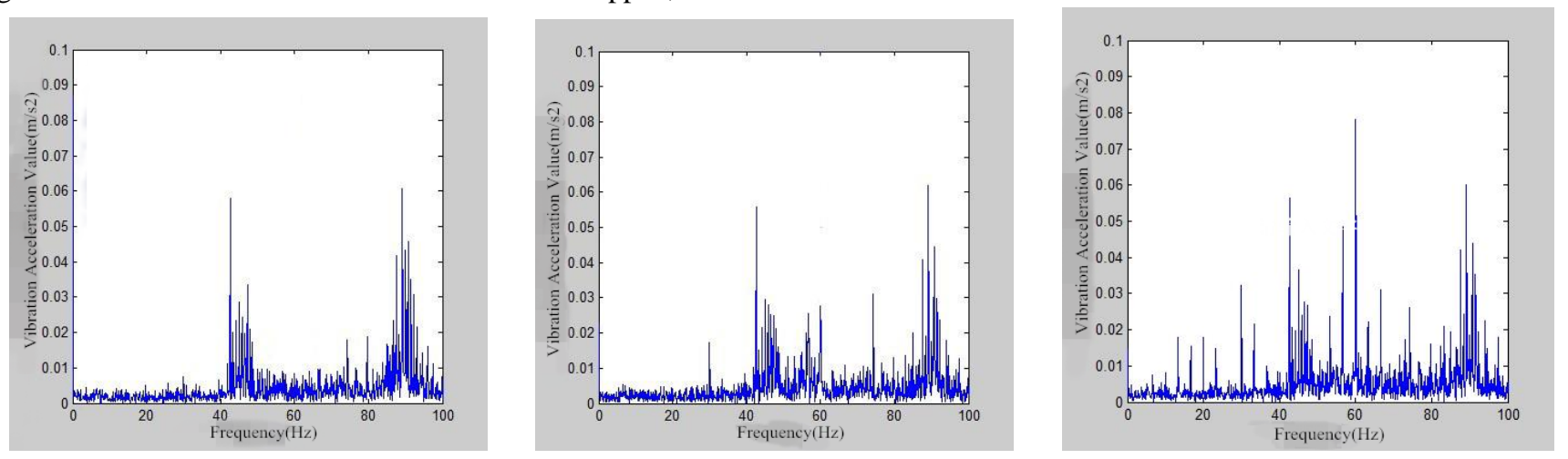

FIGURE X. A SPECTRUM AT THE BEGINNING, B SPECTRUM AT 10S, C SPECTRUM AT 4000S

After the processing of frequency spectrum thinning [5], the amplitude of the meshing frequency and 2 times the meshing frequency and the amplitude of the two sides of the frequency are extracted to form a one-dimensional vector, as showing in table I.

TABLE I ONE-DIMENSIONAL VECTOR

\begin{tabular}{|c|c|c|}
\hline & $(23.3,26.7,30,33.3,36.7)$ & $(53.3,56.7,60,63.3,66.7)$ \\
$(\mathrm{Hz})$
\end{tabular}

When $10 \mathrm{~s}$, the characteristic vectors near $30 \mathrm{~Hz}$ are $(-0.4$, $-0.84,1.25,0.25,-0.5)$, and only the center frequency increases; the characteristic vectors near $60 \mathrm{~Hz}$ are $(2.25,1.8,2.33,0.125,4.5)$, where the edge frequency also increased, therefore, the judgment of the gear is uniform wear, the local wear is not obvious but has begun. When 4000s, the characteristic vectors near $30 \mathrm{~Hz}$ are $(14,0,3.125,4.5,4)$, the center frequency and the edge frequency amplitude are very obvious; the characteristic vectors near $60 \mathrm{~Hz}$ are $(5,3.9,7.89,1.875,15)$, amplitude had very obvious growth, it is an obvious modulation phenomenon [6], shown that the gear has produced a serious local wear.

Figure XI is the result of the end of the trial. Through the evaluation of the feature vector, we can know that the gear 
appeared uniform wear at first, with the aggravation of the fault, the local wear is serious. At the end of the test, found cracks in the drive axle main gear teeth, obvious wear and spalling on the tooth surface, it verified the conclusion of the process of broken teeth.
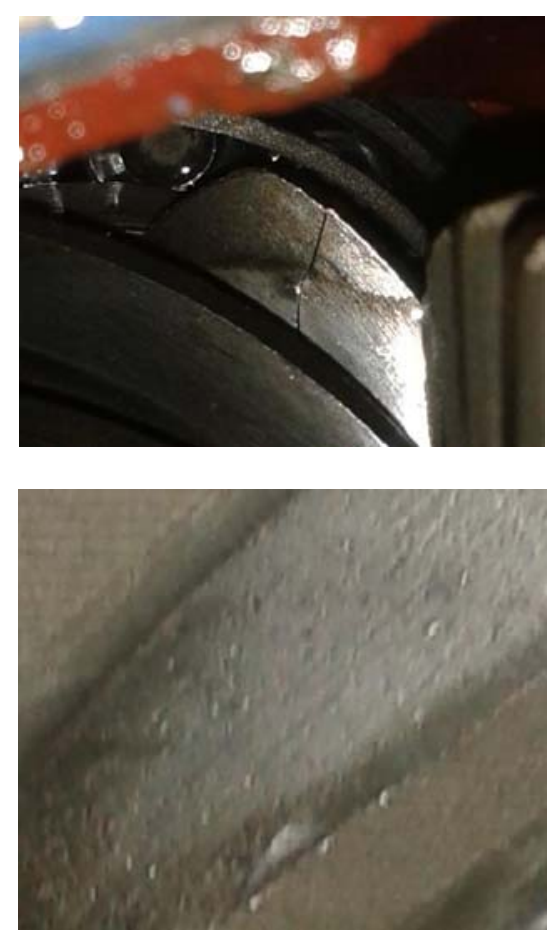

FIGURE XI. RESULT OF THE TRIAL

\section{CONCLUSION}

The fault diagnosis system has been put into use in the drive axle and transmission fatigue test bench, which can meet the requirements of issuing early warning and giving a diagnosis. After the bench test for several months, it has accumulated abundant test data, verify the reliability of the system and the system is constantly improved at the same time.

\section{REFERENCES}

[1] Sun,H.Q. Research on online fault diagnosis of gearbox bearing [D]. Hefei: College of mechanical engineering, HeFei University of Technology, 2010.

[2] Jin,S.X \& Jin,Z.S. Distribution characteristics and fault diagnosis of gear vibration [J]. Journal of Vibration Engineering, 1999.03.022:430-432.

[3] Zhao,S.X, Zhang,L.B \& Wang,Z.H. Study on short term prediction of equipment rotating parts [J]. Mechanical Strength, 2005,27 (5):575-579.

[4] D.Ho and R.B.Randall. Optimization of bearing diagnostic techniques using simulated and actual bearing fault signals[J].Mechanical Systems and SignalProcessing,2000,14(5):763-788.

[5] Ding,K. Comparison of spectrum analysis between ZFFT and Chirp2Z refinement of the selected bands [J]. Vibration and Shock, 2006,25 (6):9-12.

[6] Wang,Y.C, Xie,M \& Ding,K. Envelope analysis method and its application in gearbox fault diagnosis [J]. Journal of Chongqing University, 1995,18 (1): 87-91. 